\title{
Trainingen voor klinische docenten
}

\author{
R.P. Zwierstra, Th.E. Fick
}

\section{Samenvatting}

Inleiding: In dit artikel wordt ingegaan op argumenten, die de noodzaak van structurele docenttrainingen in het medisch opleidingscontinuüm onderstrepen. Aan de hand van de literatuur komen enkele rollen, modellen en domeinen aan de orde, die onderscheiden kunnen worden in relatie tot klinische docenttaken en er worden voorbeelden van trainingsprogramma's voor docenten gegeven.

Beschouwing: De continue veranderende context waarin opgeleid wordt en de moderne inzichten in de aanpak van onderwijs en opleiding brengen met zich mee, dat een herbezinning op de rol van de arts als docent en opleider op z'n plaats is. Vanuit verschillende invalshoeken worden inhoudelijke elementen aangegeven voor didactische programma's en wordt de relevantie voor de praktijk onderbouwd.

Conclusie: Een docent of opleider, die voor die taak geen specifieke scholing heeft gehad, kan die taak bij een hedendaags opleidingscontinuüm voor 'de arts van straks' en 'de specialist van morgen' niet meer naar behoren uitvoeren. (Zwierstra RP, Fick ThE. Trainingen voor klinische docenten. Tijdschrift voor Medisch Onderwijs 2004;23(1):51-56.)

\section{Inleiding}

Klinisch werkzame docenten zijn doorgaans competente beroepsbeoefenaren, van wie vakkennis een eerste (en tot op heden vaak ook enige) vereiste is om klinisch docent te kunnen zijn. Het hebben van didactische bekwaamheid wordt zelden als voorwaarde gesteld voor het uitvoeren van een onderwijs- of opleidingstaak. Kennelijk wordt er impliciet van uit gegaan, dat klinische expertise vanzelf leidt tot goed doceren. In veel ziekenhuizen maakt het verzorgen van onderwijs en opleiding een substantieel deel uit van de dagelijkse werkzaamheden van medisch specialisten en arts-assistenten, al dan niet in opleiding. Herhaaldelijk wordt in de literatuur aangegeven dat op dit gebied verbeteringen nodig of gewenst zijn, zoals o.a. blijkt uit een uitspraak van Calman: "We need to look again at how doctors learn and how teaching methods can be improved in order that time spent in education can be used efficiently." 1

Tegenwoordig worden aan opleidingen en opleiders in toenemende mate hogere eisen gesteld, zoals het formuleren van eindtermen, het opstellen van doelmatige en doeltreffende opleidingsprogramma's, het ontwerpen en afnemen van goede toetsen, et cetera. In de hedendaagse initiële én vervolgopleiding zullen we dan ook moeten streven naar opleiders en klinische docenten, die specifiek voor die taak zijn opgeleid.

In dit artikel gaan wij in op argumenten, die de noodzaak van structurele docenttrainingen in het medisch opleidingscontinuüm onderstrepen, bespreken we enkele niveau's, die onderscheiden kunnen worden in relatie tot klinische docenttaken en geven we enkele voorbeelden van trainingsprogramma's voor docenten. 


\section{Veranderend perspectief}

In de geneeskunde is verandering eerder regel dan uitzondering. Die veranderingen betreffen zowel humaan biologische concepten, diagnostische technieken, behandelingsmethoden als sociaal maatschappelijke en economische gezondheidsdeterminanten. Maar veranderingen zijn er ook in het onderwijs: curricula en opleidingsprogramma's zijn fundamenteel veranderd, aangepast aan veranderde inhoudelijke en didactische inzichten, met onder andere vroeg in het curriculum meer inzet van klinische docenten. Daarnaast moet de 'arts van straks' in staat gesteld worden om in kortere tijd aan de eindtermen van de opleiding te voldoen. ${ }^{2}$ Hetzelfde geldt voor de 'specialist van morgen', waarbij de arbeidstijdenwet en de mogelijkheid van het volgen van deeltijdopleidingen de opleiding gecompliceerder maken. ${ }^{3}$ Daarbij wordt niet alleen in een kortere tijd opleiding genoten, ook zijn vergeleken met een decennium geleden de aantallen studenten en assistentgeneeskundigen-in-opleiding (AGIO's) sterk gestegen.

Ook het Centraal College Medische Specialismen (CCMS), de Huisarts en Verpleeghuisarts Registratie Commissie (HVRC) en de Concilia van de wetenschappelijke verenigingen besteden veel aandacht aan de herziening van de vervolg opleidingsprogramma's. Eén en ander vergt een herbezinning op de doelmatigheid en doeltreffendheid van de vervolg opleidingsprogramma's.

In de rapporten 'De arts van straks' en 'De zorg van morgen' is duidelijk aangegeven, dat opleiders didactisch geschoold moeten worden en dat de didactische kwaliteiten op peil gehouden moeten worden en regelmatig moeten worden geëvalueerd. ${ }^{2} 4$

Op het gebied van de didactiek hebben zich ontwikkelingen voorgedaan en zijn inzichten veranderd die geleidelijk aan in onze beroepsgroep worden herkend en gelukkig ook erkenning hebben gevonden. $^{2}$

In Nederland heeft Boendermaker binnen de huisartsgeneeskunde onderzoek gedaan naar de huisartsopleider. Hij spreekt over een tweede beroep wanneer een huisarts ook opleider wil zijn. En dat tweede beroep vraagt specifieke bekwaamheden, waarvoor een opleiding noodzakelijk is. Het gevolg van die opleiding is dat de huisarts niet alleen een beter opleider wordt (dus in staat is zijn kennis beter over te dragen), maar ook een beter didactisch rolmodel krijgt. Daarbij zal het opleiderschap leiden tot meer reflectie, waardoor meer verdieping ontstaat in het eigen handelen, wat tot groter werkplezier en een betere kwaliteit van handelen tot gevolg kan hebben. ${ }^{5}$

Bolhuis heeft recent in dit tijdschrift een uiteenzetting gegeven over de veranderde inzichten op het gebeid van het leren in de praktijk. Zij wijst op een noodzakelijke koppeling in inhoud en tijd tussen theoretisch onderwijs en praktijk, zowel in de initiële als in de vervolgopleiding. Tevens legt zij de nadruk op het belang van reflectie op de praktijkervaringen teneinde het leerproces te versterken. ${ }^{6}$

Terwijl de meeste van de huidige docenten en opleiders curricula hebben gevolgd, waarbij het overdragen van kennis en vaardigheden op de voorgrond heeft gestaan, gaat het nu in het medisch opleidingscontinuüm om het zelf vergaren van kennis en vaardigheden en zijn daarnaast hele andere begrippen toegevoegd: 'lifelong learning', professioneel gedrag, competentie, feedback, reflectie, portfolio, et cetera. Een goede klinische docent of opleider zal zich die begrippen door didactische bijscholing toch eigen moeten maken om ze te kunnen toepassen. 
Zowel uit de literatuur als uit de dagelijkse praktijk blijkt dat in deze tijd van verandering en ontwikkeling op onderwijsgebied een fundamentele herbezinning op de rol van de arts als docent en opleider op z'n plaats is. Een docent of opleider die voor die taak geen specifieke scholing heeft gehad kan die taak niet naar behoren uitvoeren. Onder andere Boendermaker en Prideaux geven duidelijk aan dat een dergelijke scholing zowel voor de onderwijspraktijk als voor de medische praktijk positieve effecten oplevert. 510

\section{De theorie}

De voornaamste veranderingen die zich in het medisch onderwijs van de laatste decennia hebben voorgedaan zijn: geïntegreerde curricula, "problem based learning', kern- en keuze curricula, meer accenten op extramurale gezondheidszorg. Meer in het oog springend zijn echter de veranderde opvattingen ten aanzien van de rol van de student en van de docent: meer aandacht voor 'learning' door de student dan voor 'teaching' door de docent. De taak van de docent is daarmee complexer geworden: zij stijgt ver uit boven die van het lesgeven alleen.

In een publicatie van de Association for Medical Education in Europe (AMEE) zijn de verschillende rollen van de docent uiteengezet (zie figuur 1). ${ }^{7}$ Vanuit de traditionele rol van medisch expert als 'information provider' wordt die van 'role model' en die van 'facilitator' (coach) toegevoegd. De meeste docenten hebben als beoordelaar of examinator tevens een rol in de toetsing of in het evaluatieproces ('assessor') en een aantal ook als cursusof programmacoördinator ('planner'). Een enkeling is betrokken bij de ontwikkeling van onderwijsonderdelen of van leermiddelen. Vanuit dit model kunnen verschillende niveau's van inhoudelijke betrokkenheid worden vastgesteld, waaraan de benodigde expertise op didactisch en onderwijskundig gebied kan worden gekoppeld. Het model is van wezenlijke waarde om de verschillende rollen te expliciteren, de eraan verbonden competenties te identificeren en daartoe programma's samen te stellen.

Hesketh, et al. hebben een indeling in drie kennis- en vaardigheidsdomeinen

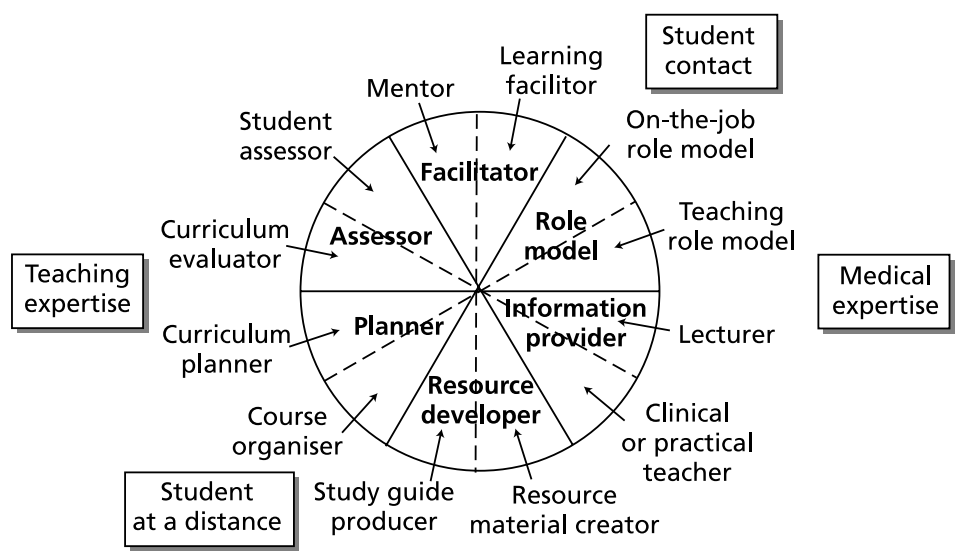

Figuur 1. Uit: Harden RM, Crosby J. AMEE Guide No. 20: The good teacher is more than a lecturer. Med Teach 2000;22:3344-47. Met toestemming van de uitgever Taylor \& Francis Ltd., http://www.tandf.co.uk/journals/ titles/0142159X.html. 
met verschillende niveau's opgesteld, waar zij concrete leerdoelen aan koppelen. ${ }^{8}$ Het eerste domein ("What the doctor as a teacher is able to do") betreft uitvoerende onderwijstaken en deze variëren van doceren (laagste niveau) tot en met het evalueren van onderwijsactiviteiten of cursussen (hoogste niveau in deze groep). Het tweede domein ("How the doctor approaches his/her teaching") regardeert de leertheorieën, kennis van emotionele intelligentie en 'evidence based medical education'. Het derde domein ("The doctor as a professional teacher") omvat de maatschappelijke en persoonlijke oriëntatie. Dit model biedt eveneens een uitstekend raamwerk voor enerzijds programmaopbouw en anderzijds voor docenten om leemten in didactische kennis en vaardigheden te identificeren.

Irby heeft aan de hand van interviews met en observaties van uitstekende docenten een aantal 'kennisgebieden' geïdentificeerd die essentieel blijken te zijn voor het verzorgen van uitstekend klinisch onderwijs. Die gebieden zijn: medische kennis in de vorm van ziektescripts, kennis van actuele patiëntcasus, bewustzijn van het belang van context, op de hoogte zijn van het kennisniveau van de studenten en kennis van didactische principes, waaronder het geven van feedback. ${ }^{9}$

Prideaux gaat in zijn artikel uit van het CanMEDS 2000-model waarin de zes bekwaamheden zijn weergegeven waarover de arts dient te beschikken teneinde de eisen die de maatschappij stelt het hoofd te kunnen bieden. ${ }^{10}$ Die zes bekwaamheden (medical expert, communicator, collaborator, manager, health advocate, scholar en professional) zullen volgens Prideaux niet alleen als eindtermen in de opleiding gehanteerd dienen te worden, zij dienen bovenal ter explicitering van het rolmodel dat de opleider heeft ten aanzien van de studenten en assistenten. Een docent die zich bewust is van deze rollen, werkt daarmee tevens aan zijn rol als competent arts voor de patiënten.

Welke thema's van belang zijn voor de docent voor de alledaagse onderwijs- en opleidingspraktijk is onder andere onderzocht door McLeod en medewerkers. ${ }^{11} \mathrm{Zij}$ hebben uiteindelijk een lijst samen kunnen stellen van kernthema's, te beschouwen als de minimale didactische bagage van elke docent, waarover dertien ervaren docenten overeenstemming wisten te bereiken. De thema's waren: (a) curriculumdoelstellingen en opbouw, (b) principes van het leren door volwassenen, (c) principes van leermethoden om volwassenen te helpen met leren en (d) beoordeling en toetsing. Uit de commentaren van de deelnemende docenten kwam naar voren dat er redenen zijn om aan te nemen dat kennis van onderwijskundige principes docenten gevoeliger maakt voor het proces van 'teaching en learning'. Het leidt tot het geven van beter onderwijs, van effectiever onderwijs, en bovenal tot meer plezier in het geven van onderwijs, hetgeen zowel een verhoogde docent- als studentsatisfactie tot gevolg heeft.

De beschreven rollen, modellen en domeinen in bovenstaande bescheiden literatuuroverzicht zijn goed als leidraad te gebruiken bij de benodigde didactische professionalisering van klinische docenten en opleiders.

\section{De praktijk}

Bij alle herzieningen van geneeskundecurricula en medisch specialistische opleidingen en de groeiende aandacht voor docentprofessionalisering zijn specifieke scholingsactiviteiten voor de bijbehorende docentenrollen onontbeerlijk. Uit boeken valt veel te leren en goede, op de praktijk gerichte boeken over medisch 
onderwijs zijn verkrijgbaar. ${ }^{12-15}$ Maar om praktische ervaring op te kunnen doen en gedachten en expertise uit te kunnen wisselen is het volgen van cursussen, waar de benodigde kennis en vaardigheden worden aangereikt, nog steeds dé aangewezen weg. Vele onderwijsinstellingen, al dan niet verbonden aan Universitair Medische Centra (UMC's), hebben de nodige curriculum specifieke cursussen in hun programma of zijn (naar alle waarschijnlijkheid) in staat om cursussen 'op maat' of 'vraaggestuurd' te ontwikkelen. Deze 'locale' cursussen zijn zeer geschikt om een goed klinisch docent 'op de werkvloer' te kunnen worden en vaak worden ze op één of meerdere dagdelen gegeven. Daarna zijn coaching, intervisie, feedback en reflectie belangrijke elementen om didactisch bij te kunnen blijven.

Naast bovengenoemde scholingsmogelijkheden zijn er de laatste jaren een aantal specifieke cursussen beschikbaar, gericht op het opleiderschap cq. het docentschap in opleidingsklinieken. Deze cursussen bevatten één of meerdere 'vertaalde' modules van de Engelstalige cursussen 'Training the trainers: learning and teaching' en 'Appraissal and assessment' van The Royal College of Surgeons. Initiatieven voor het geven van deze cursussen zijn genomen in Groningen, Leiden en Sittard en binnen de Nederlandse Vereniging voor Medisch Onderwijs (NVMO) wordt de haalbaarheid van het landelijk aanbieden van deze cursussen onderzocht. De kracht van deze cursussen is gelegen in het creëren van een veilige leeromgeving waarin door actieve participatie geoefend wordt met methoden om doeltreffend en doelmatig studenten en assistenten te begeleiden en te beoordelen. Uit de evaluaties van de cursus blijkt dat naast het opdoen van didactische kennis en vaardigheden ook (weer) enthousiasme en plezier in het opleiden wordt ervaren. Binnen de huisartsopleiding worden op landelijk niveau vergelijkbare cursussen voor huisartsopleiders verzorgd.

Daarnaast organiseert de NVMO cursussen die veelal de plaatselijk geboden onderwerpen overstijgen en zowel op de initiële als op de vervolgopleidingen gericht zijn (zie NVMO-cursussen op http:// www.nvmo.nl). Ook organiseert deze vereniging in de maand november een jaarlijks onderwijscongres, waar steeds vaker onderwerpen gerelateerd aan de vervolgopleidingen aan de orde komen.

\section{Tenslotte}

In dit artikel hebben wij argumenten aangedragen voor de noodzaak van didactische trainingen voor docenten: de continue veranderende context waarin opgeleid wordt en de moderne inzichten in de aanpak van onderwijs en opleiding. Tevens zijn vanuit verschillende invalshoeken inhoudelijke elementen aangegeven voor de didactische programma's en is de relevantie voor de praktijk onderbouwd. Ook is een kort overzicht van de bestaande mogelijkheden gepresenteerd.

Willen wij echter komen tot een didactische kwalificatie van docenten op verschillende niveau's, dan is het beschrijven van de noodzaak ervan, de relevantie voor de praktijk en het ontwikkelen en aanbieden van programma's niet voldoende. Krachtige ondersteuning op bestuurlijk niveau en koppeling van docentkwalificatie aan functiewaarderingssystemen en beloningssystematiek is een belangrijke voorwaarde om didactische professionalisering uit de sfeer van vrijblijvendheid naar de werkelijkheid van vanzelfsprekendheid te krijgen. Het is daarbij bemoedigend dat het beloningsaspect duidelijk benoemd is in de rapporten 'De arts van straks' en 'De zorg van morgen' en dat op 
ministerieel niveau wordt nagedacht over een algemene opzet van een opleidingsfonds, een nieuw systeem van financiering van de zorgopleidingen. ${ }^{2} 4$

\section{Literatuur}

1. Working Group on Specialist Medical Training (K. Calman, chairman). Hospital doctors: training for the future. London: Dept. of Health; 1993.

2. Meijboom-de Jong B, Schmit Jongbloed LJ, Willemsen MC, editors. De arts van straks - een nieuw medisch opleidingscontinuüm. Utrecht: KNMG/ DMW-VSNU/VAZ/NVZ/LCVV; oktober 2002.

3. Bleker OP. De specialist van morgen; een betere opleiding. Tijdschrift voor Medisch Onderwijs 2003;22(4):174-9.

4. LeGrand-van den Bogaard MJM, Rooijen APN van, editors. De zorg van morgen - flexibiliteit en samenhang. Rapport van de Commissie Implementatie Opleidingscontinuüm en Taakherschikking. Den Haag: Ministerie van VWS; juli 2003.

5. Boendermaker PM. Meesterschap, van verkenning naar herkenning van de goede huisartsopleider. Maarssen: Elsevier Gezondheidszorg; 2003.

6. Bolhuis S. Professioneel leren: wat is het en hoe bevorderen we het? Tijdschrift voor Medisch Onderwijs 2002;21(4):173-82.

7. Harden RM, Crosby J. AMEE Guide No. 20: The good teacher is more than a lecturer. Med Teach 2000;22:334-47.

8. Hesketh EA, Bagnall G, Buckley EG, Friedman M, Goodall E, Harden RM, et al. A framework for developing excellence as a clinical educator. Med Educ 2001;35:555-64.
9. Irby DM. What clinical teachers in medicine need to know. Acad Med 1994;69:333-42.

10. Prideaux D, Alexander H, Bower A, Dacre J, Haist S, Jolly B, et al. Clinical Teaching: maintaining an educational role for doctors in the new health care environment. Med Educ 2000;34:820-6.

11. McLeod PJ, Steinert Y, Meagher T, McLeod A. The ABCs of pedagogy for clinical teachers. Med Educ 2003;37:638-44.

12. Cate ThJ ten, Bleker OP, Büller HA, Scherpbier AJJA. Opleiden van medisch specialisten. Achtergronden en praktijk. Houten: Bohn Stafleu Van Loghum; 2003.

13. Dent JA, Harden RM, editors. A practical guide for medical teachers. Edinburgh: Churcill Livingstone; 2001.

14. Peyton JWR, editor. Teaching and learning in medical practice. Rickmansworth: Manticore, 1998.

15. Metz JCM, Scherpbier AJJA, Vleuten CPM van der. Medisch onderwijs in de praktijk. Assen: Van Gorcum; 1995.

\section{De auteurs:}

Prof. dr. R.P. Zwierstra is directeur van het Onderwijsinstituut van de Faculteit der Medische Wetenschappen te Groningen.

Th.E. Fick, chirurg, is verbonden aan het Onderwijsinstituut van het UMC Utrecht en voorzitter van de Commissie Professionalisering Docenten van de Nederlandse Vereniging voor Medisch Onderwijs.

\section{Correspondentieadres:}

Th.E. Fick, chirurg, Onderwijsinstituut UMC Utrecht, Universiteitsweg 100, 3584 CG Utrecht, tel:030-2538225, t.e.fick@med.uu.nl.

\section{Summary}

Introduction: The authors discuss the arguments underpinning the necessity, induced by the changes in medical education, of structural training courses for teachers involved in today's medical education continuum. An overview is given of some roles, models and domains in relation to the role of the clinical teacher and some training courses are mentioned.

Reflection: The continuous changes and modern concepts in medical education warrant serious reflection on the role of the clinical teacher.

Conclusion: Without educational training, today's clinical teacher will not be able to fulfil his or her role properly in the current undergraduate and postgraduate medical education curricula for the training of medical doctors and specialists. (Zwierstra RP, Fick ThE. Training for clinical teachers. Dutch Journal of Medical Education 2004;23(1):51-56.) 